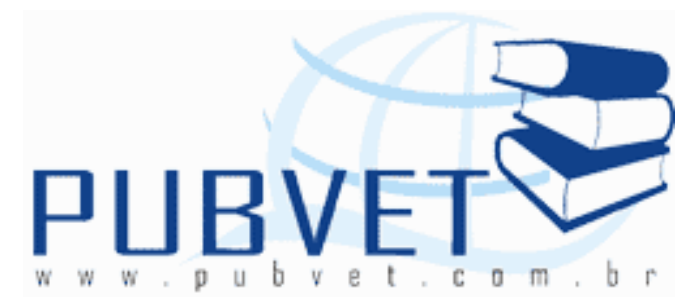

PUBVET, Publicações em Medicina Veterinária e Zootecnia.

\title{
Resposta de Paspalum atratum cv. Pojuca a níveis de potássio
}

Newton de Lucena Costa ${ }^{1}$, Claudio Ramalho Townsend ${ }^{2}$, Ricardo Gomes de Araújo Pereira ${ }^{2}$, João Avelar Magalhães ${ }^{3}$, Valdinei Tadeu Paulino ${ }^{4}$, Antônio Neri Azevedo Rodrigues ${ }^{5}$, Lucia Elenícia da Silva Nascimento ${ }^{6}$

${ }^{1}$ Eng. Agr., D.Sc., Embrapa Roraima, Boa Vista, RR.

${ }^{2}$ Zootec., D.Sc., Embrapa Rondônia, Porto Velho, RO.

${ }^{3}$ Méd. Vet., D.Sc., Pesquisador da Embrapa Meio-Norte, Parnaíba, PI.

${ }^{4}$ Eng. Agr., Ph.D, Instituto de Zootecnia, Nova Odessa, SP.

5 Eng. Agr., M.Sc., IFRO. Colorado do Oeste, RO. Doutorando em Agronomia/Produção Vegetal, UFPR. Curitiba, PR.

${ }^{6}$ Estudante de Pós-Graduação em Gestão Ambiental e Ecoturismo, Faculdade Montenegro. Parnaíba, PI.

\section{Resumo}

O efeito de níveis de potássio $\left(0,15,30,45\right.$ e $60 \mathrm{mg} / \mathrm{dm}^{3}$ de $\mathrm{K}$ ) sobre o rendimento de matéria seca (MS) e composição química de Paspalum atratum cv. Pojuca foi avaliado sob condições de casa-de-vegetação. A adubação potássica incrementou significativamente os rendimentos de MS e teores de potássio, ocorrendo o inverso quanto aos teores de proteína bruta e fósforo. 0 máximo rendimento de MS foi obtido com a aplicação de $52,8 \mathrm{mg} / \mathrm{dm}^{3}$ de $\mathrm{K}$, enquanto que os maiores teores de PB e potássio foram registrados com a aplicação de 51,7 e $37,8 \mathrm{mg} / \mathrm{dm}^{3}$ de $\mathrm{K}$, respectivamente. O nível crítico interno de potássio, relacionado a $90 \%$ da produção máxima de MS, foi estimado em 
$1,72 \%$ de $K$, o qual foi obtido com a aplicação de $42,3 \mathrm{mg} / \mathrm{dm}^{3}$. A eficiência de utilização de potássio e os teores de cálcio e magnésio não foram afetados $(P>0,05)$ pelos níveis de potássio utilizados.

Palavras-chave: cálcio, fósforo, magnésio, matéria seca, potássio, proteína bruta

\title{
Response of Paspalum atratum cv. Pojuca to potassium fertilization
}

\begin{abstract}
The effect of potassium levels $\left(0,15,30,45\right.$ and $60 \mathrm{mg} / \mathrm{dm}^{3}$ of $\mathrm{K}$ ) on dry matter (DM) yield and chemical composition of Paspalum atratum cv. Pojuca, was evaluated under greenhouse conditions. $K$ fertilization significantly increased DM yields and potassium contents, while crude protein and phosphorus contents were depressed. Maximum DM yield and crude protein, and potassium contents were obtained with the application of $52.8 ; 51.7$ and $37.8 \mathrm{mg} / \mathrm{dm}^{3}$ of $\mathrm{K}$, respectively. Internal potassium requirement for $90 \%$ maximum DM yield was estimated at $1.72 \%$ of $K$, corresponding to application of $42.3 \mathrm{mg} / \mathrm{dm}^{3}$ of $\mathrm{K}$. The potassium efficiency and calcium and magnesium contents did not affected ( $P>0.05)$ by potassium levels.
\end{abstract}

Keywords: calcium, crude protein, dry matter, magnesium, phosphorus, potassium

\section{Introdução}

Estabelecido através de sementes, o capim Paspalum atratum Swallen cv. Pojuca é uma gramínea forrageira perene, adaptada a solos ácidos e de baixa fertilidade, indicada para áreas úmidas de baixadas sujeitas a alagamento temporário, ou mesmo para localidades com altas precipitações pluviométricas (KALMBACHER et al., 1997; LEITE \& FERNANDES, 1999). No entanto, ele tem bom desempenho também na pré-Amazônia e nas regiões Central, Norte e Sul do Cerrado (EMBRAPA CERRADOS, 2000). Suas características de alta produção de forragem, boa aceitação por bovinos e 
COSTA, N.L. et al. Resposta de Paspalum atratum cV. Pojuca a níveis de potássio. PUBVET, Londrina, V. 6, N. 29, Ed. 216, Art. 1438, 2012.

eqüinos e boa resistência ao ataque da cigarrinha-das-pastagens (Deois flavopicta Stall.) (EMBRAPA CERRADOS, 2000; LEITE et al., 2001), entre outras, fazem com que o capim-pojuca seja uma boa alternativa a outras gramíneas forrageiras.

O potássio é um mineral de grande importância para a manutenção e a recuperação da produtividade das pastagens. É ativador de várias enzimas e está relacionado com a distribuição de água e com o transporte de carboidratos na planta. Ao contrário do fósforo, é um elemento bastante móvel no solo, sendo também absorvido, principalmente, por difusão (EPSTEIN, 1975; MALAVOLTA, 1980; MARSCHENER, 1995; TAIZ \& ZEIGER, 1998).

Os solos de Rondônia apresentam, originalmente, teores médios ou altos de potássio trocável, sendo rara a resposta de gramíneas forrageiras à adubação potássica. No entanto, face ao uso de práticas de manejo inadequadas (elevadas cargas animais, sistema de pastejo contínuo e ausência de fertilizações de estabelecimento e/ou manutenção), as quais afetam consideravelmente a eficiência dos processos de reciclagem de nutrientes e induzindo o aparecimento de deficiência de potássio nas pastagens cultivadas. (COSTA et al., 2007; COSTA et al., 2012).

Ensaios exploratórios de fertilidade do solo realizados na região Amazônica demonstraram que o potássio, depois do fósforo, foi o nutriente mais limitante ao crescimento de Paspalum atratum cv. Pojuca e Panicum maximum cvs. Mombaça e Centenário, reduzindo significativamente seus rendimentos de forragem, perfilhamento, teores de proteína bruta e potássio (COSTA, 1996; COSTA et al., 2003). Em pastagens de Brachiaria brizantha cv. Marandu, estabelecidas em solo com baixa disponibilidade de potássio (51 $\mathrm{mg} / \mathrm{kg}$ ), Costa (1996), com a aplicação de $40 \mathrm{~kg}$ de $\mathrm{K}_{2} \mathrm{O} / \mathrm{ha}$, obtiveram incrementos de $65 ; 38$ e $81 \%$, respectivamente para os rendimentos de forragem e quantidades acumuladas de potássio e nitrogênio.

Neste trabalho avaliaram-se os efeitos da fertilização potássica sobre a produção de forragem e a composição química de Paspalum atratum cv. Pojuca. 
COSTA, N.L. et al. Resposta de Paspalum atratum cv. Pojuca a níveis de potássio. PUBVeT, Londrina, V. 6, N. 29, Ed. 216, Art. 1438, 2012.

\section{Material e Métodos}

O ensaio foi conduzido em casa-de-vegetação, utilizando-se um Latossolo Amarelo, textura argilosa, o qual apresentava as seguintes características químicas: $\mathrm{pH}=4,8 ; \mathrm{Al}=1,3 \mathrm{cmol} / \mathrm{dm}^{3} ; \mathrm{Ca}+\mathrm{Mg}=1,7$ $\mathrm{cmol} / \mathrm{dm}^{3} ; \mathrm{P}=2 \mathrm{mg} / \mathrm{kg}$ e $\mathrm{K}=33 \mathrm{mg} / \mathrm{kg}$. O solo foi coletado na camada arável ( 0 a $20 \mathrm{~cm}$ ), destorroado e passado em peneira com malha de $6 \mathrm{~mm}$ e posto para secar ao ar.

O delineamento experimental foi em blocos casualizados com quatro repetições. Os tratamentos consistiram de cinco doses de potássio $(0,15,30$, 45 e $60 \mathrm{mg} / \mathrm{dm}^{3}$ de solo), aplicadas sob a forma de cloreto de potássio, quando do plantio e uniformemente misturadas com o solo. A adubação de estabelecimento constou da aplicação de $22 \mathrm{mg} / \mathrm{dm}^{3}$ de $P$, sob a forma de superfosfato triplo. Cada unidade experimental constou de um vaso com capacidade para 3,0 $\mathrm{dm}^{3}$ de solo seco. Dez dias após a emergência das plantas executou-se o desbaste, deixando-se três plantas/vaso. O controle hídrico foi realizado diariamente através da pesagem dos vasos, mantendo-se o solo em $80 \%$ de sua capacidade de campo. Durante o período experimental foram realizados três cortes a intervalos de 45 dias e a $15 \mathrm{~cm}$ acima do solo.

Os parâmetros avaliados foram rendimento de matéria seca (MS), teores de nitrogênio, fósforo, potássio, cálcio e magnésio. Foram ajustadas as equações de regressão para rendimento de MS (variável dependente) e teor de potássio (variável independente) (equação 1) e para teor de potássio como variável dependente dos níveis de potássio aplicados (equação 2). Através da equação 1 calculou-se a dose de potássio aplicada relativa a $90 \%$ do rendimento máximo de $M S$, sendo este valor substituído na equação 2 para determinação do nível crítico interno de potássio.

\section{Resultados e Discussão}

A adubação potássica afetou significativamente $(P<0,05)$ os rendimentos de MS da gramínea, sendo os maiores valores obtidos com a aplicação de 60 $(5,73 \mathrm{~g} /$ vaso $)$ e $45 \mathrm{mg} / \mathrm{dm}^{3}$ de $\mathrm{K}(5,34 \mathrm{~g} /$ vaso $)$. No entanto, a aplicação de 15 
COSTA, N.L. et al. Resposta de Paspalum atratum cv. Pojuca a níveis de potássio. PUBVeT, Londrina, V. 6, N. 29, Ed. 216, Art. 1438, 2012.

$\mathrm{mg} / \mathrm{dm}^{3}$ de $\mathrm{K}$ já proporcionou um incremento de $145 \%$ em relação à testemunha (Tabela 1 ).

Tabela 1. Rendimento de matéria seca (MS) e eficiência de utilização do potássio (EUK) de Paspalum atratum cv. Pojuca, em função da fertilização potássica.

\begin{tabular}{ccc}
\hline Níveis de $\mathrm{K}\left(\mathrm{mg} / \mathrm{dm}^{3}\right)$ & MS $(\mathrm{g} /$ vaso $)$ & EUK $(\mathrm{mg} \mathrm{de} / \mathrm{g}$ de $\mathrm{MS})$ \\
\hline 0 & $1,74 \mathrm{~d}$ & --- \\
15 & $4,27 \mathrm{c}$ & $15,90 \mathrm{a}$ \\
30 & $4,75 \mathrm{bc}$ & $17,40 \mathrm{a}$ \\
45 & $5,34 \mathrm{ab}$ & $16,70 \mathrm{a}$ \\
60 & $5,73 \mathrm{a}$ & $16,30 \mathrm{a}$ \\
\hline
\end{tabular}

- Médias seguidas de mesma letra não diferem entre si $(P>0,05)$ pelo teste de Tukey.

Os rendimentos de forragem ajustaram-se ao modelo quadrático de regressão ( $\left.y=1,96+0,13976 x-0,001324 x^{2} ; R^{2}=0,97\right)$. A dose de máxima eficiência agronômica foi estimada em $52,8 \mathrm{mg} / \mathrm{dm}^{3}$ de $\mathrm{K}$, a qual foi inferior às relatadas por Gutteridge (1978) para Brachiaria mutica $\left(87 \mathrm{mg} / \mathrm{dm}^{3}\right)$ e Costa (1996) para B. brizantha cv. Marandu $\left(57,6 \mathrm{mg} / \mathrm{dm}^{3}\right)$.

A eficiência de utilização de potássio não foi afetada $(P>0,05)$ pelas doses aplicadas (Tabela 1). Resultados semelhantes foram obtidos por Costa et al. (2003) para P. maximum cv. Centenário. Os teores de fósforo foram ajustados ao modelo quadrático de regressão $(\hat{y}=0,1738+0,00045 x-$ $0,000001 x^{2} ; R^{2}=0,81$ ), sendo o máximo teor obtido com a aplicação de 22,5 $\mathrm{mg} / \mathrm{dm}^{3}$ de $\mathrm{K}$. Andrade et al. (1996) constataram efeitos negativos do potássio sobre os teores de fósforo, sem influenciar os teores de PB de Brachiaria ruziziensis. 


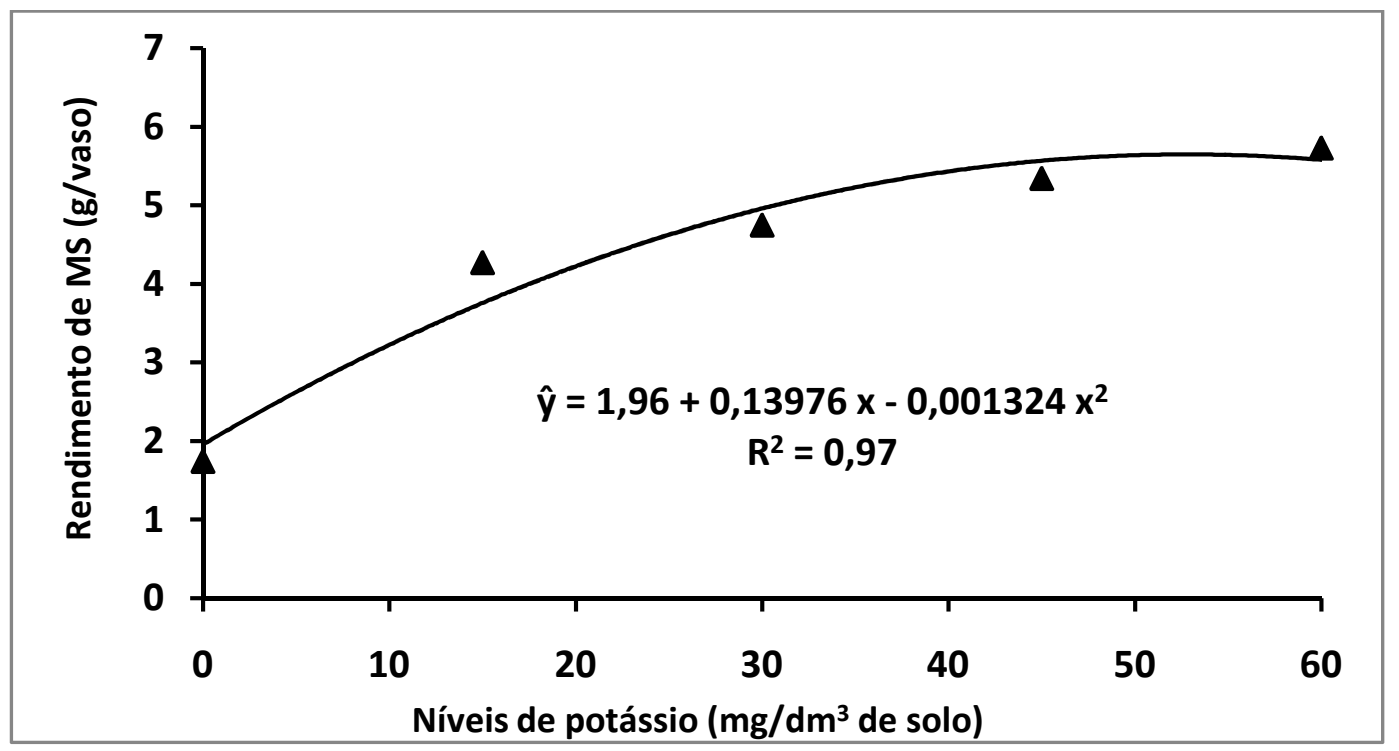

Figura 1. Rendimento de matéria seca de Paspalum atratum cv. Pojuca, em função dos níveis de potássio.

Os teores de cálcio e magnésio não foram influenciados $(P>0,05)$ pela adubação potássica (Tabela 2). Contudo, considerando-se que não houve diluições com o aumento dos rendimentos de MS, observa-se um efeito positivo da adubação potássica na manutenção dos teores destes nutrientes. A análise regressão revelou os efeitos da adubação potássica sobre os teores de PB $\left(\hat{y}=11,52+0,31 x-0,003 x^{2} ; R^{2}=0,95\right)$ e potássio $(\hat{y}=1,294+0,0227 x$ - 0,0003 $\left.x^{2} ; R^{2}=0,96\right)$, sendo os maiores valores obtidos com a aplicação de 51,7 e $37,8 \mathrm{mg} / \mathrm{dm}^{3}$ de $\mathrm{K}$, respectivamente (Figuras 2 e 3). Considerando-se que teores de PB inferiores a 7\% limitam a fermentação ruminal (MINSON et al., 1984), neste experimento as respostas da gramínea às doses de $\mathrm{K}$ testadas atenderiam satisfatoriamente esta exigência.

Em geral, as concentrações de macronutrientes registradas para a gramínea são semelhantes às reportadas por Silva et al. $(1995 a, b)$ para Andropogon gayanus cv. Planaltina e P. maximum cv. Tobiatã. 
Tabela 2. Teores de fósforo, cálcio, magnésio e potássio (\%) de Paspalum atratum cv. Pojuca, em função da fertilização potássica.

Níveis de $\mathrm{K}$ $\left(\mathrm{mg} / \mathrm{dm}^{3}\right)$

Fósforo

Cálcio

Magnésio

Potássio

\begin{tabular}{ccccc}
\hline 0 & $0,173 \mathrm{~b}$ & $0,68 \mathrm{a}$ & $0,40 \mathrm{a}$ & $1,28 \mathrm{c}$ \\
15 & $0,179 \mathrm{a}$ & $0,76 \mathrm{a}$ & $0,41 \mathrm{a}$ & $1,59 \mathrm{~b}$ \\
30 & $0,181 \mathrm{a}$ & $0,79 \mathrm{a}$ & $0,37 \mathrm{a}$ & $1,74 \mathrm{a}$ \\
45 & $0,170 \mathrm{~b}$ & $0,80 \mathrm{a}$ & $0,43 \mathrm{a}$ & $1,67 \mathrm{ab}$ \\
60 & $0,167 \mathrm{~b}$ & $0,83 \mathrm{a}$ & $0,44 \mathrm{a}$ & $1,63 \mathrm{ab}$ \\
\hline
\end{tabular}

- Médias seguidas de mesma letra não diferem entre si $(P>0,05)$ pelo teste de Tukey.

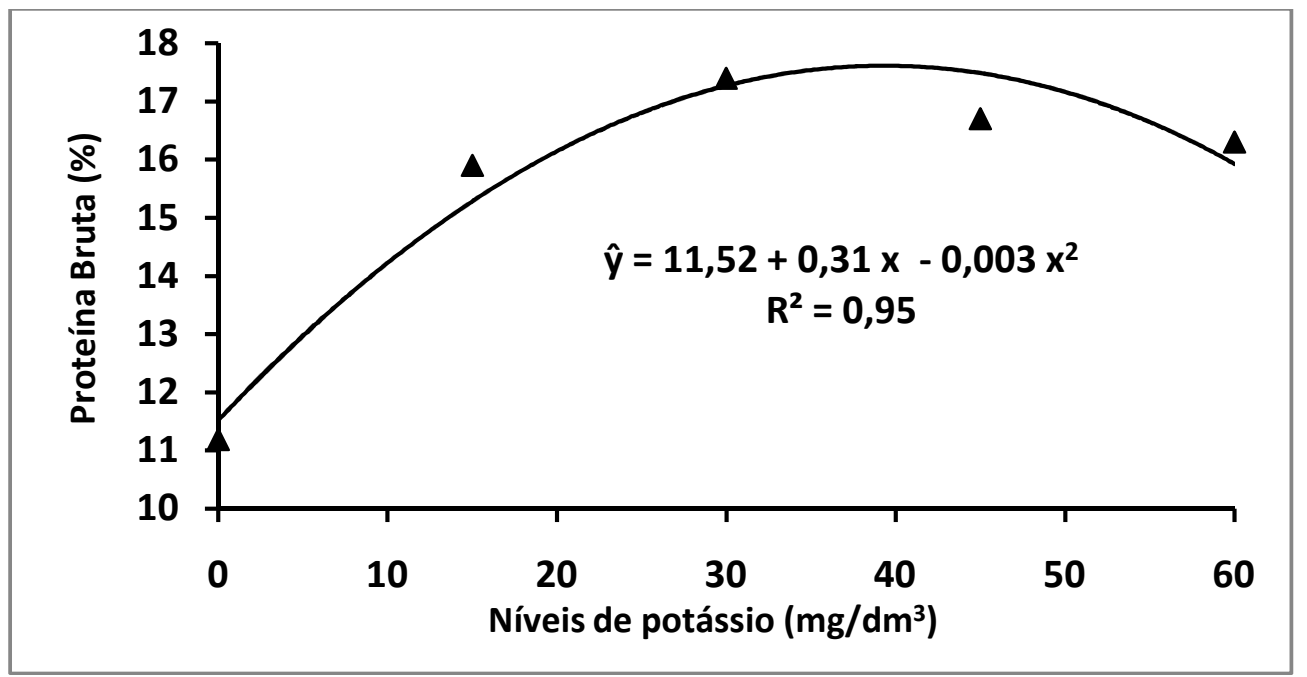

Figura 2. Teores de proteína bruta do Paspalum atratum cv. Pojuca, em função dos níveis de potássio. 


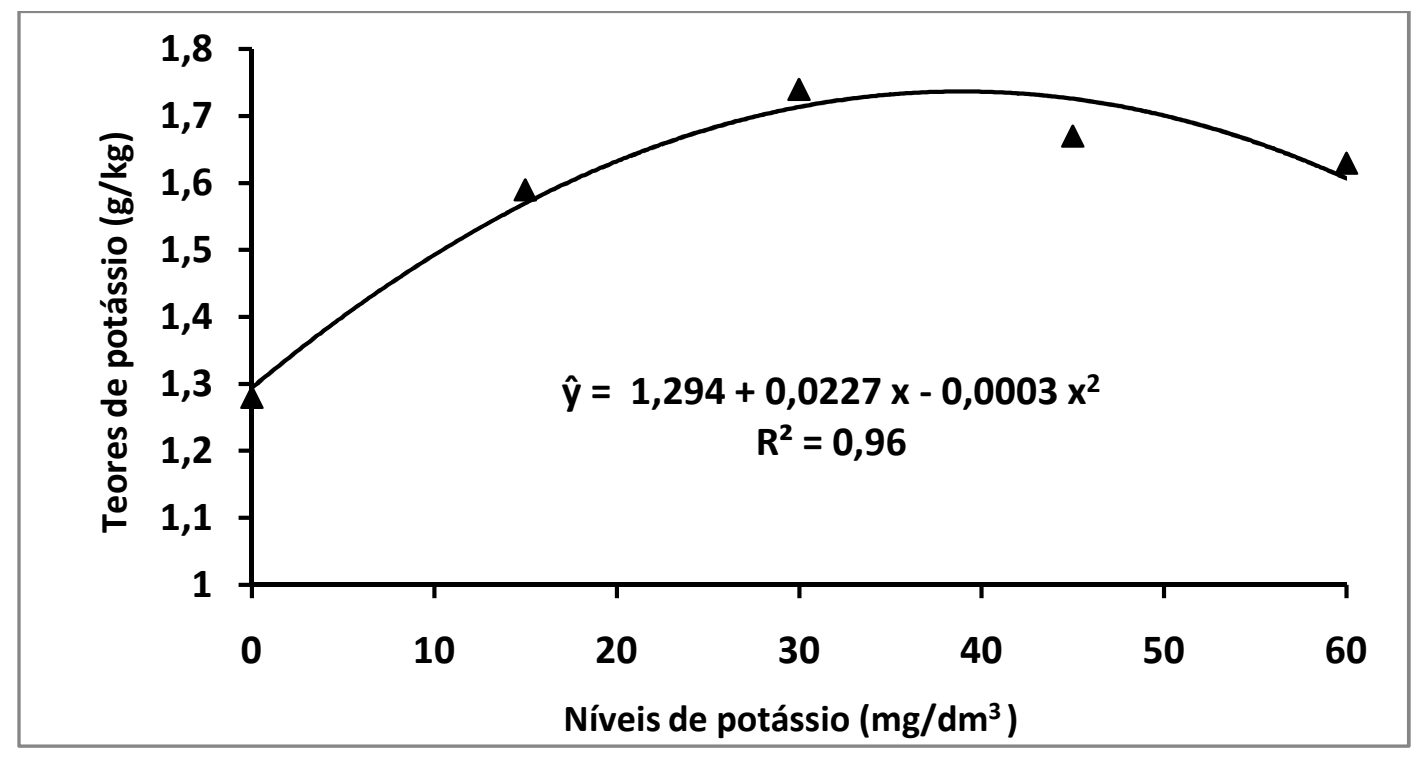

Figura 3. Teores de potássio do Paspalum atratum cv. Pojuca, em função dos níveis de potássio.

O nível crítico interno de potássio, determinado através da equação que relacionou a dose de potássio necessária para a obtenção de $90 \%$ do rendimento máximo de MS, foi estimado em 1,72\%, o qual foi obtido com a aplicação de $42,3 \mathrm{mg} / \mathrm{dm}^{3}$ de K. Este valor é superior aos relatados por Toledo (1986) para Hyparrhenia rufa $(1,15 \%)$, A. gayanus $(0,95 \%)$, B. brizantha $(0,82 \%)$ e B. humidicola $(0,74 \%)$.

\section{Conclusões}

A adubação potássica incrementou os rendimentos de MS e os teores de $\mathrm{K}$, ocorrendo o inverso quanto aos teores de $\mathrm{N}$ e $\mathrm{P}$.

A dose de máxima eficiência agronômica foi estimada em $52,8 \mathrm{mg} / \mathrm{dm}^{3}$ de $\mathrm{K}$ e o nível crítico interno, relacionado com $90 \%$ do rendimento máximo de MS em $1,72 \%$.

A eficiência de utilização de $\mathrm{K}$ e os teores de $\mathrm{Ca}$ e $\mathrm{Mg}$ não foram afetados pelos níveis de $\mathrm{K}$ utilizados. 


\section{Referências Bibliográficas}

ANDRADE, J.B.; BENINTENDE, R.P.; FERRARI JÚNIOR, E.; PAULINO, V.T.; HENRIQUE, W.; WENER, J.C.; MATTOS, H.B. Efeito das adubações nitrogenada e potássica na produção e composição de Brachiaria ruziziensis. Pesquisa Agropecuária Brasileira, v.31, n.9, p.617620, 1996.

COSTA, N. de L. Programa de pesquisa com pastagens em Rondônia. Porto Velho: Embrapa Rondônia, 1996. 24p. (Embrapa Rondônia. Documentos, 32).

COSTA, N. de L.; TOWNSEND, C.R.; PEREIRA, R.G.A.; MAGALHÃES, J.A.; SILVA NETTO, F.G.; TAVARES, A.C. Tecnologias para a produção animal em Rondônia - 1975/2001. Porto Velho, Embrapa Rondônia, 2003. 26p. (Embrapa Rondônia. Documentos, 70).

COSTA, N de L.; MAGALHAES, J.A.; PEREIRA, R.G.A.; TOWNSEND, C.R.; OLIVEIRA, J.R.C. Considerações sobre o manejo de pastagens na Amazônia Ocidental. Revista do Conselho Federal de Medicina Veterinária, Brasília, v.13, n.40, p.37-56, 2007.

COSTA, N. de L.; MAGALHÃES, J.A.; CARNEIRO, M.S.S.; MAGALHÃES, J.A.; XAVIER, T.F.; NASCIMENTO, L.E. da S.; FURTADO, F.M.V. Produção e composição química de Panicum maximum cv. Mombaça sob diferentes níveis de potássio. Pubvet, Londrina, v.6, N.28, Art\#1387, 2012.

EMBRAPA CERRADOS. Capim Pojuca (Paspalum atratum), capim nativo de alta produção e qualidade. Embrapa Cerrados, Brasília, DF, 6p. 2000. (Folder)

EPSTEIN, E. Nutrição mineral das plantas: princípios e perspectivas. São Paulo: EDUSP, 1975. 341p.

GUTTERIDGE, R.C. Potassium fertilizer studies on Brachiaria mutica/Centrosema pubescens pastures grown on acid soils derived from coral limestone, Malaita, Solomon Islands. Tropical Agriculture, v.58, n.1, p.359-367, 1978.

KALMBACHER, R.S.; BROWN, W.F.; COLVIN, D.L.; DUNAVIN, L.S.; KRETSCHEMER JUNIOR, A.E.; MARTIN, F.G.; MULLAHEY, J.J.; RECHCIGL, J.E. Suerte atra Paspalum: its management and utilization. Gainesville: University of Florida, 15p. 1997. (Florida Agricultural Experiment Station, Circular S-397).

LEITE, G.G.; FERNANDES, F.D. Qualidade da forragem do capim Paspalum atratum cv. Pojuca. Brasília: Embrapa Cerrados, 4p. 1999. (Comunicado Técnico, 9).

LEITE, G.G.; FERNANDES, F.D.; GOMES, A.C. Crescimento e composição química de capim Paspalum atratum cv. Pojuca. Brasília: Embrapa Cerrados, 22p. 2001. (Boletim de Pesquisa e Desenvolvimento, 19).

MALAVOLTA, E. Elementos de nutrição mineral de plantas. São Paulo: Agronômica Ceres, 1980. $251 \mathrm{p}$.

MARSCHENER, H. Mineral nutrition of higher plants. 2. ed. London: Academic Press, 1995. 889p.

MINSON, D.J. Effects of chemical and physical composition of herbaje eaten upon intake. In: HACKER, J.B. (Ed.) Nutritional limits to animal production from pasture. Farnham Royal: CAB. p.167-182, 1984. 
SILVA, N.M.A.; SILVEIRA, R.I.; GOMIDE, C.A.; LIMA, C.G. Produção e composição mineral de gramíneas forrageiras submetidas à níveis de potássio, cálcio e sódio. I. Capim-andropogon cV. Planaltina. In: CONGRESSO BRASILEIRO DE CIÊNCIA DO SOLO, 25., 1995, Viçosa. Anais... Viçosa: SBCS, 1995a. p.1051-1053.

SILVA, N.M.A.; SILVEIRA, R.I.; GOMIDE, C.A.; LIMA, C.G. Produção e composição mineral de gramíneas forrageiras submetidas à níveis de potássio, cálcio e sódio. II. Capim-colonião cV. Tobiatã. In: CONGRESSO BRASILEIRO DE CIÊNCIA DO SOLO, 25., 1995, Viçosa. Anais... Viçosa: SBCS, 1995b. p.1054-1056.

TAIZ, L.; ZEIGER, E.N. Plant physiology. Sunderland: Sinauder Associates, 792p. 1998.

TOLEDO, J.M. Pasturas en trópico húmedo: perspectiva global. In: SIMPÓSIO DO TRÓPICO ÚMIDO, I., Belém, 1984. Anais... Belém: EMBRAPA-CPATU, 1986. v.5. Pastagem e Produção Animal, p.19-35. 